\title{
Saberes y estrategias de adaptación a la disponibilidad hídrica en las yungas secas del norte de Chile ${ }^{1}$
}

\author{
Knowledge and strategies of adaptation to water \\ availability in the dry yungas of the north of Chile
}

\author{
Mónica Soledad Meza Aliaga², Karem Angélica Pereira Acuña ${ }^{3}$ \\ y Juan Gabriel Jofré Cañipa ${ }^{4}$
}

\begin{abstract}
RESUMEN
El aprovechamiento de los cursos superficiales e intermitentes de agua que en el pasado del norte de Chile desarrollaron comunidades asentadas en la yunga seca de la región de Arica y Parinacota, evidencian saberes y capacidad de organización para incorporar nuevos espacios de cultivo mediante estrategias de manejo ambiental. Bajo el actual escenario de cambio climático, cobra importancia la capacidad adaptativa que las comunidades poseen y poseerán, para lo cual es significativo relevar prácticas que demostraron ser efectivas para enfrentar la variabilidad del clima. Utilizando métodos etnográficos y revisión de fuentes etnohistóricas y climáticas, se caracterizan las prácticas de cultivos estacionales y manejo de crecidas en las quebradas de Apanza y Livilcar, aproximándose al patrón de variabilidad climática que estimuló la adaptación de sus comunidades. Los resultados muestran que el clima de la región pretérito y proyectado; presenta una recurrencia de periodos con mayor y menor disponibilidad de agua. En consecuencia, el desuso de estas prácticas adaptativas se hallaría ligado a la conexión esporádica que actualmente las personas mantienen con los territorios que estimularon estrategias particulares y comunitarias de manejo de los recursos, esto en el marco del proceso de descampesinización y urbanización acontecido en la región.
\end{abstract}

Palabras clave: Adaptación a la variabilidad climática, desuso de prácticas agrícolas, Codpa, Timar, Livilcar.

\begin{abstract}
Communities who settled in the dry yunga of the Arica and Parinacota region in northern Chile, from the pre-Hispanic past knew how to take advantage of the superficial and intermittent watercourses, thereby demonstrating knowledge and organizational capacity to incorporate new crop spaces through strategies of environmental management. Under the current climate change scenario, the adaptive capacity that communities possess and will possess is important. For this reason, it is significant to highlight the practices that have proven effective in confronting climate variations. Using ethnographic methods and a review of ethnohistoric and climatic sources, seasonal practices of crop and flood management are characterized in the Apanza and Livilcar ravine, approaching the pattern of climatic variability that stimulated the adaptation of their communities. The results show that the region's past and projected climate present a recurrence of periods with greater and lesser availability of water just like when these practices were employed. Consequently, the disuse of adaptive practices can be linked to the sporadic connection that people currently maintain with the territories which stimulated strategies for resource management, within the context of 'de-peasantization' and urbanization experienced by in the region.
\end{abstract}

Key words: Adaptation to climate variability, disuse of agricultural practices, Codpa, Timar, Livilcar. 
Chile es un país social, económica y ambientalmente susceptible a los cambios climáticos. Para el caso del Norte Grande chileno, donde se localiza el Desierto de Atacama, las características de extrema aridez constituyen un factor condicionante si se piensa en los efectos futuros y potenciales del cambio climático en la región; donde se estima una exacerbación de procesos ya existentes como degradación y salinización de suelos, erosión hídrica y eólica, procesos de sedimentación e inundaciones (Gutiérrez, 1998; Romero et al., 2017).

La hidrología de los sistemas de drenaje superficiales y subterráneos del Norte Grande tiene una función esencial en relación con la continuidad espacial de las aguas entre sectores altos y bajos (Klohn, 1972; Romero et al., 2013), pues las aguas provenientes de precipitaciones en cuencas altiplánicas atraviesan procesos de escurrimiento superficial, infiltración hacia cuencas subterráneas y evaporación por la fuerte radiación (Yáñez \& Molina, 2011). La intensidad y periodicidad de las precipitaciones que se originan en las cuencas altiplánicas es determinante para la recarga de las cuencas bajas (Dirección General de Aguas, 2011), de ahí que cualquier cambio ambiental en esta franja ecológica de altura es de importancia estratégica, pues repercutirá verticalmente en los pisos de precordillera, yunga seca ${ }^{5}$ v valles costeros.

Las características geográficas y ambientales propias del norte de Chile motivaron desde la institucionalidad la formulación y aplicación de políticas, planes y programas para el manejo y aprovechamiento de los recursos agua y suelo, apuntando al desarrollo, modernización e integración de la región al sistema capitalista (Taberna, 1996).

En el Chile moderno, la gestión del agua se remonta al año 1951 con la creación del primer Código de Aguas que concibió este recurso como bien nacional de uso público reglamentándolo a partir derechos de aprovechamiento. Este código de aguas estuvo vigente hasta que, en dictadura el año 1981, se promulgó el actual Código de Aguas que cambió el paradigma, favoreciendo la gestión del agua mediante su apropiación y comercialización a través de monopolios empresariales que marginan el acceso a sectores sociales pobres e indígenas, grupos que, en el ámbito local del norte de Chile, se sirvieron por años de la gestión comunitaria del agua bajo lógicas redistributivas.

Ya en la década de 1960, el carácter intermitente de la disponibilidad hídrica en los valles costeros del norte de Chile, se planteó como un problema para mantener una agricultura competitiva, iniciándose una serie de acciones tendientes a canalizar y trasvasar agua desde zonas altas. Tras años de intentos fallidos, en 1962 se concretó el proyecto de canalización del río Lauca, que tuvo como resultado mantener un flujo de aguas permanente aumentando el caudal del río San José y con ello, la expansión de la superficie agrícola en el valle de Azapa. Se trasvasaron aguas desde las lagunas de Cotacotani hacia el caudal del San José para abastecer a la agricultura y el consumo de la creciente población de Arica. Además, el potencial hídrico del altiplano fue aprovechado mediante la construcción de una central hidroeléctrica en la sierra de Chapiquiña.

\footnotetext{
Corresponde a "las tierras de clima cálido de los valles y quebradas que trepan al Ande inmediatamente después de la Chala", estas a su vez, son "las tierras que se encuentran ubicadas de forma contigua al mar por el lado occidental de la cordillera de los Andes y a los valles y quebradas de igual clima que se extienden en el declive oriental andino" (Pulgar, 2014: 5). El nombre asignado a este piso ecológico se origina en el saber geográfico indígena y se diferencia de las clasificaciones clásicas del espacio andino como costa, precordillera y montaña (Dollfus, 1981; Pulgar, 2014).
} 
Frente al carácter estratégico de la alta montaña andina para el ciclo del agua de la región de Arica y Parinacota, cobra importancia la variabilidad climática del Altiplano, esta variabilidad se halla caracterizada por una gran amplitud térmica y régimen de precipitaciones estivales asociadas al monzón sudamericano, y donde las proyecciones futuras para el norte de Chile difieren entre quienes plantean una disminución de la precipitación (Gaete, 2005; Garreaud, 2011) y quienes vislumbran un aumento (Fuenzalida et al., 1989; CONAMA 1999, 2006, 2008).

En virtud de estas proyecciones, adquiere cada vez más importancia la capacidad adaptativa de las comunidades frente a las condiciones e incertidumbres, tanto propias de la variabilidad del sistema climático, como de aquéllas forzadas por la actividad humana.

En este sentido, resulta interesante conocer cómo comunidades agrícolas en el norte de Chile, desplegaron desde épocas prehispánicas prácticas de uso y manejo ambiental y productivo ancladas en la observación y experimentación del espacio geográfico. Dichas prácticas dan cuenta de un exhaustivo conocimiento de los ecosistemas locales y de las restrictivas condiciones hídricas, permitiéndoles adaptar las particularidades del territorio y generar estrategias en su beneficio para enfrentar perturbaciones, especialmente climáticas (Platt, 1975; Santoro et al., 1998).

Como evidencia de estas prácticas de manejo, es posible mencionar los cultivos estacionales o de temporada ${ }^{6}$ y las técnicas empleadas para el control y manejo de los Huaycos o Llocllas; ; ambas permitieron evitar el daño a cultivos e infraestructura debido a las crecidas de agua en la yunga seca de la región de Arica y Parinacota (Keller, 1946; Urzúa 1969; Platt, 1975; Ríos \& Pizarro, 1988; Van Kessel \& Condori, 1992; Reyes, 2011; Tarque, 2016; Jofré, 2017).

Estas prácticas se encontraban asociadas a mecanismos de complementariedad vertical y estrategias de diversificación de recursos entre pisos altitudinales y microclimas, permitiendo a las poblaciones ampliar su acceso a recursos (disponibilidad de agua, espacios de cultivo, alimentos, mano de obra, tecnologías); lo cual se entiende como un proceso de ajuste del sistema humano al clima o adaptación climática, necesaria además para mantener los medios de reproducción para la vida cotidiana en los territorios.

En lo relativo a la adaptación al cambio climático, cabe destacar que esta ha sido pensada como un proceso de toma de decisiones de top down, sin embargo, durante varias décadas, investigadores han reflexionado acerca de que este enfoque es limitado y es cada vez más evidente para la comunidad científica que la adaptación es ante todo un proceso local (Hofstede, 2014; Noblet et al., 2016), que involucra "cambios en los sistemas socio-ecológicos en respuesta a impactos pasados y/o anticipados de cambio climático" (Noblet et al., 2016: 2).

En este sentido, se considera que la práctica de cultivos estacionales y manejo de crecidas de río, actualmente en desuso, constituyen estrategias y formas históricas de adaptación cultu-

Práctica agrícola mediante la cual se aprovechaban las avenidas de agua en períodos de lluvia para cultivar en suelos disponibles y que han sido documentadas por Keller, 1946; Platt, 1975; González, 1990; Santoro et al., 1998 y González et al., 2014.

De acuerdo con Bertonio, 2011 el significado de la palabra lloclla (del aymara lluxlla) es avenida o diluvio. Posee otros derivados como lluxlla wat'aña (encharcarse con avenida o diluvio), uma lluxllajauti (avenida de ríos) y uma lluxlla (creciente de avenida). 
ral y no sólo en relación con los actuales efectos del cambio climático ${ }^{8}$, sino como un proceso político-social que media entre los individuos y los colectivos y su manera de enfrentar cambios socioambientales (Eriksen et al., 2015). Por tanto, el uso, distribución y acceso a los recursos, se hallan determinados no sólo por su disponibilidad, sino también por procesos políticos y económicos internos y externos que sugieren la activación, y se debe añadir la desactivación, de formas de adaptación según las estructuras sociales que agencian estos procesos (Gallopín, 2006; Adger, 2000; Nelson, 2011; McDowell \& Hess, 2011).

Partiendo de la premisa que existe una diversidad de formas de concebir y enfrentar la variabilidad climática en función de los contextos geográficos y culturales específicos, y más aún en el actual escenario de cambio climático, las preguntas de investigación formuladas son: ¿cuáles eran las características de éstos cultivos de temporada y cómo eran las condiciones climáticas que estimularon la práctica de los cultivos estacionales en la yunga seca del Norte Grande de Chile?, ¿se espera que las condiciones climáticas futuras en el norte de Chile sean muy distintas de aquéllas que activaron estas prácticas de adaptación en el pasado?, ¿influyó el escenario demográfico del área de estudio en el desuso de estas prácticas adaptativas?.

Para responder estas preguntas se inicia presentando el área de estudio y la metodología para luego dar cuenta, gracias al uso de métodos etnográficos, de la existencia en el pasado de estas prácticas adaptativas y sus características, pues constituyen evidencia de ajustes efectivos de las comunidades de Timar, Codpa y Livilcar (Figura $\mathrm{N}^{\circ} 1$ ) frente a la variabilidad del clima y del acceso al agua. Como segundo punto, se realiza una aproximación mediante fuentes secundarias y desde el pasado prehispánico, a las condiciones climáticas representadas por la alternancia de eventos que estimularon la adaptación de estas comunidades, conjuntamente se muestran los resultados de estudios climáticos que evidencian tendencias y proyectan el escenario climático para el norte de Chile; esto con el propósito de entender si las prácticas adaptativas de interés cobran sentido en función de las condiciones climáticas esperadas. Finalmente, se presentan datos que dan cuenta de la dinámica demográfica del área de estudio.

\section{Materiales y método}

\section{Área de estudio}

Se localiza en un piso ecológico de transición entre la sierra alta y el piedemonte denominado yunga seca con posición entre los 1.000 y 2.000 m.s.n.m en la región de Arica y Parinacota en el Norte Grande de Chile (Figura No 1). Este piso se caracteriza por la existencia de un microclima con fuerte insolación, baja nubosidad y menor pluviosidad con respecto a geosistemas de mayor altitud (precordillera y altiplano) debido a su posición de abrigo dentro de una cadena de cerros (Dollfus, 1981).

La quebrada de Livilcar se ubica al sureste de la ciudad de Arica y presenta una fuerte erosión en cañadas producto del material sedimentario que ha sido arrastrado por las avenidas de agua

Si bien estas comunidades también han enfrentado otros fenómenos climáticos como sequías, este estudio se enfoca principalmente en los fenómenos de crecida y avenida de agua que estimularon las prácticas adaptativas escogidas para el análisis. 
en sectores encajonados del valle ${ }^{9}$. En su prolongación existen una serie de asentamientos que en la actualidad se hallan prácticamente deshabitados ${ }^{10}$, pero en el pasado las comunidades de los poblados incorporaban espacios de la cabecera del valle de Azapa para la práctica de los cultivos estacionales.

Por su parte, los poblados de Timar y Codpa, vinculados en el pasado a la quebrada de Apanza"1 para la práctica de dichos cultivos, se ubican al sureste de la ciudad de Arica en la cuenca de Vítor o Codpa entre los 1.800 y 2.000 m.s.n.m. y poseen lluvias esporádicas de bajos montos máximos. Actualmente, tanto en Livilcar como en Timar y Codpa, las comunidades ${ }^{12}$ practican una agricultura de producción familiar, gracias al microclima y a las características de suelo, pues la angostura de las quebradas sólo posibilita cultivar en restringidos espacios utilizando sistemas de eras ${ }^{13}$ y terrazas que dependen enteramente del riego (Keller, 1946; Muñoz et al., 1987; González, 1990).

Desde épocas prehispánicas, en la quebrada de Livilcar se efectuó la práctica de los cultivos estacionales, mientras que en Apanza los antecedentes indican que desde la década de 1940. Esta práctica de cultivos ha sido situada por Platt (1975) y Durston \& Hidalgo (2004) como dentro de un sistema mayor de complementariedad ecológica.

Durante los meses del verano austral (diciembre a marzo), el altiplano andino recibe los mayores aportes hídricos provenientes de las precipitaciones convectivas que en esta temporada alcanzan su mayor intensidad y máximo desplazamiento hacia el sur, posibilitando que la recarga hídrica recibida (napas subterráneas, escorrentía superficial y subterránea), se infiltre en el curso medio o inferior de los valles, escurriendo vía subterránea y emergiendo más abajo como vertientes que forman ríos locales y quebradas (Klohn, 1972, Romero et al., 2013). La intensidad y frecuencia de estas precipitaciones altiplánicas es influenciada por la presencia del ENOS (El Niño Oscilación Sur), fenómeno que durante sus fases cálidas o El Niño, produce una disminución de la precipitación en el altiplano ocurriendo lo contrario durante su fase fría o La Niña (Rutllant et al., 1992; Aceituno \& Montecinos, 1992; Aceituno, 1996; Garreaud et al., 2003).

Es así como mediante la conexión aguas arriba-aguas abajo, en las cuencas de la región se conforma una red integrada de recursos hídricos (ríos, lagos, lagunas, vertientes, aguadas) que forman parte de un mismo sistema de aprovechamiento de aguas que es utilizada por las comunidades para su reproducción social, económica y cultural, así como para la gran minería que se desarrolla en gran parte de las regiones del norte chileno (García, 2008; Yáñez \& Molina, 2011; Romero et al., 2013), y que constituye una actividad que en los últimos 20 años ha desencadenado una fuerte competencia por la administración del agua.

En periodos prehispánicos estas características, además del clima de la quebrada, permitieron el cultivo de hojas de coca en algunos sectores de la quebrada de Livilcar (Platt, 1975; Dollfus, 1981; Muñoz y Chacama, 2007).

10 Sólo cuatro asentamientos hoy mantienen viviendas: Ausipar, el pueblo del Santuario de la Virgen de las Peñas, Livilcar y Humagata; los que toman vida durante la celebración de las fiestas patronales de la Virgen de las Peñas, San Bartolomé y San Santiago.

1 La quebrada de Apanza cuenta naturalmente con escurrimientos de agua superficiales de escasa magnitud, se localiza entre ambos poblados y constituye una continuación de la quebrada de Cobija.

12 Para el caso del presente estudio se entiende por comunidad de Livilcar a todas las familias que se reconocen como originarias de la quebrada de Livilcar con todos sus asentamientos.

13 Platabandas en la llanura de inundación. 


\section{Metodología}

Para caracterizar la práctica de los cultivos estacionales y manejo ambiental en las quebradas de interés, se recurrió a métodos etnográficos (Guber, 2012) que permitieron el levantamiento de entrevistas en profundidad dirigidas a informantes clave; es decir, agricultores o personas, hombres y mujeres, que hubieran practicado o conocieran sobre dichas prácticas en las quebradas de Apanza y Livilcar, a través de la historia oral familiar. De este modo se entrevistó a 41 personas (12 de Timar, 14 de Codpa y 15 de Livilcar) entre los años 2015 y 2017, y la edad de los entrevistados osciló entre 45 y 93 años. También se realizaron grupos focales coordinados con los miembros de las comunidades vinculadas a estas quebradas, utilizando para ello cartografía y registros fotográficos que incentivaran, por un lado, el diálogo en torno a las prácticas que se realizaban cotidianamente en los espacios de cultivo ampliados, y por otro las razones de su abandono. Además, hubo observación participante en terreno durante actividades comunitarias realizadas tanto en los pueblos como en la ciudad de Arica.

Estos acercamientos permitieron la aproximación a las características de las labores agrícolas en las quebradas (mano de obra, espacios y tipos de cultivo, tiempo en que se efectuaron, desplazamientos y gestión del agua). El registro de las prácticas adaptativas y saberes locales en torno a la disponibilidad hídrica a través de la oralidad de las propias comunidades permitió complementar la información ya existente en otras fuentes (documentales y estadísticas) para enriquecer el análisis.

De acuerdo con las fuentes documentales la práctica de cultivos estacionales se remonta a épocas prehispánicas en la región, sin embargo, la falta de registros climáticos para este periodo ${ }^{14}$ plantea el desafío de aproximarse a las condiciones climáticas del pasado a partir de la revisión de fuentes históricas que aporten información sobre periodos anteriores a los datos instrumentales ${ }^{15}$.

Para dar cuenta de las características climáticas del Norte de Chile y del escenario climático que en el pasado estimuló el desarrollo de estrategias de adaptación en las comunidades de Timar, Codpa y Livilcar, se revisaron fuentes documentales y etnohistóricas que permitieron visualizar el contexto climático que albergó dichas estrategias, estas proporcionaron datos de fenómenos como sequías, crecidas de ríos, avenidas de agua, llocllas, etc. La información fue organizada por año, evento climático y localización geográfica; abarcando un periodo de tiempo que fluctúa entre los siglos XVII y XXI. Además, se revisaron estudios e investigaciones estrictamente climáticas para conocer las tendencias y condiciones atmosféricas proyectadas para el norte de Chile, en tanto que la revisión de datos de población en el área de estudio también se construyó con fuentes histórico-documentales y censos de población.

\footnotetext{
Las estaciones hidrometeorológicas vigentes en el área de influencia de las quebradas de interés pertenecen a la Dirección General de Aguas (DGA) y no poseen registros antes del año 1969.

15 Métodos de reconstitución del clima utilizando fuentes históricas han sido ampliamente utilizados por investigadores como Mariano Barriendos y Javier Martín-Vide (Barriendos, 1996-1997; Barriendos y Martín-Vide, 1998; Martín-Vide y Barriendos, 1995).
} 
Figura $\mathrm{N}^{\circ} 1$

Localización de las Quebradas de Livilcar y Apanza, Región de Arica y Parinacota,

Norte Grande de Chile

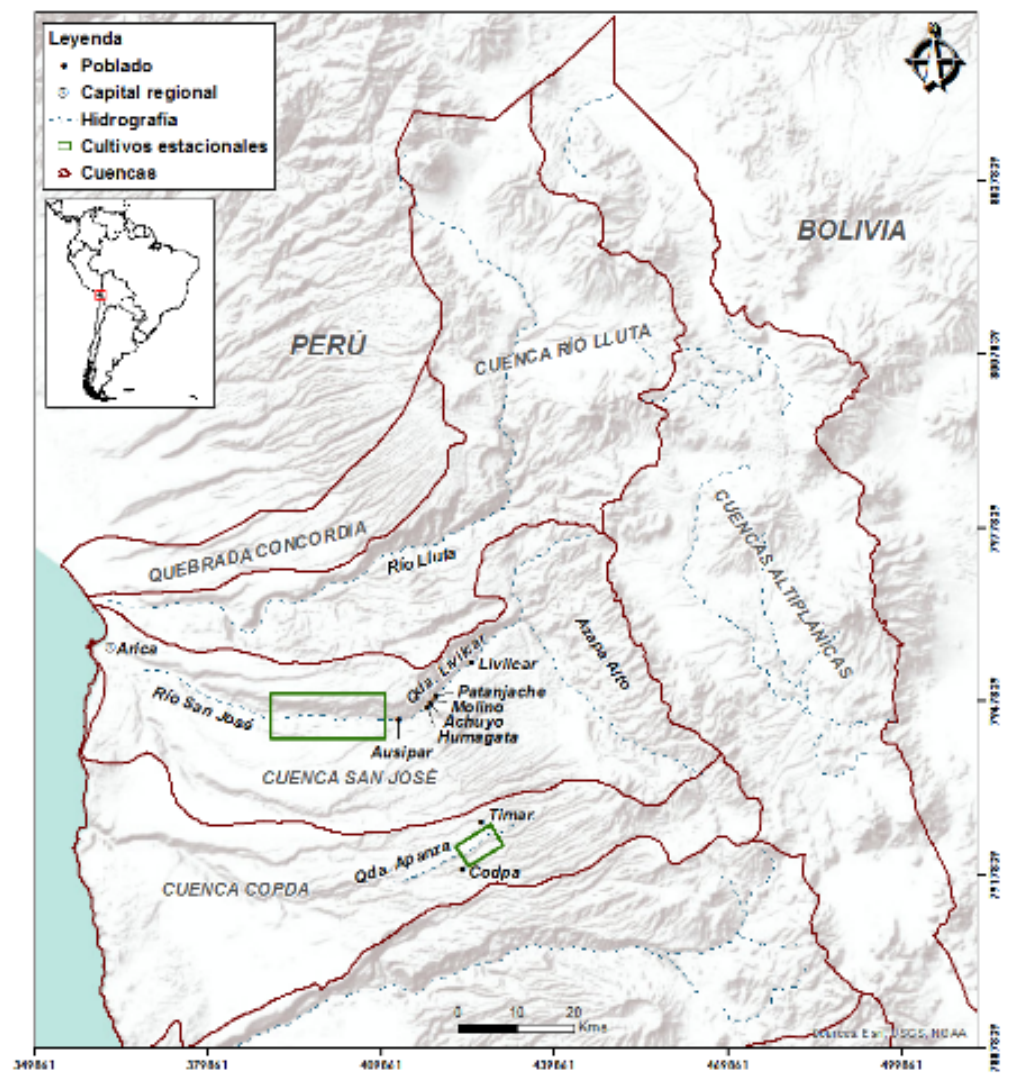

Fuente: Elaboración propia.

\section{Resultados}

\section{Estrategias locales de adaptación a la variabilidad del clima en el Norte de Chile}

Los elementos del clima interactúan en diferentes niveles y sus efectos tienen impactos directos a escala humana, principalmente para las comunidades agrícolas donde el clima es un componente más dentro de sus labores. De acuerdo con Santoro et al. (1998) el uso de tecnología hidráulica para la agricultura estacional incluía la construcción de canales de desagüe desde los periodos Intermedio Tardío y Tardío (900-1500 años d.C.), existiendo evidencias de ello en Apanza, valles de Azapa y Lluta y Pampa del Tamarugal (Platt, 1975; González, 1990; Santoro et al., 1998), mientras que el uso de terrazas se puede situar desde tiempos del incanato para aprovechar al máximo el recurso suelo de las quebradas y controlar las aguas de escorrentía. Asimismo, Platt (1975) describe el desplazamiento de comuneros entre distintos pisos ecológicos para aprovechar el excedente de recursos hídricos en los meses estivales. 
La práctica de los cultivos estacionales fue efectuada desde épocas prehispánicas (Platt, 1975; Durston \& Hidalgo, 2004) y asociada al uso archipielágico de los distintos pisos altitudinales y topoclimas de la gradiente andina (Murra, 2014; Romero et al., 2017). El uso diversificado del espacio geográfico otorgó a las poblaciones rurales la posibilidad de enfrentar la variabilidad en el acceso a los recursos y a las características restrictivas propias de cada piso ecológico, con ello disminuían la vulnerabilidad ante perturbaciones ambientales. Los terrenos de uso agrícola estacional funcionaban como un elemento dentro de un sistema económico basado en el aprovechamiento de los distintos nichos ecológicos distribuidos verticalmente entre costa y cordillera (Platt, 1975; Durston \& Hidalgo, 2004).

\section{Cultivos estacionales en la quebrada de Apanza}

De acuerdo con la memoria más remota de los pobladores de Timar y Codpa, los cultivos estacionales en la quebrada de Apanza fueron efectuados desde la década de 1940 hasta aproximadamente los años ochenta.

Las labores en la quebrada de Apanza, a la que se llegaba a pie o a lomo de animal, se iniciaban con la preparación del terreno en el mes de diciembre y duraban hasta la cosecha en junio. El proceso incluía disponer las eras de cultivo, para que recibieran el agua de las crecidas a través de obras de canalización simples que incluyeron canales, acequias y bocatomas artesanales con las que se intervenía de forma manual el curso del agua excedentaria (Figura $\mathrm{N}^{\circ} 2$ ).

Este trabajo requería de una intensa mano de obra, planeación y organización tanto individual como colectiva. De acuerdo con los relatos entregados por los informantes clave en las entrevistas levantadas, la utilización de los espacios de cultivo se realizaba en función de la proximidad a ellos, de modo tal que las personas de Timar cultivaban en la parte alta de la quebrada de Apanza y los de Codpa en los terrenos de la parte baja, sectores a los que era posible acceder utilizando senderos alternativos.

Los principales cultivos eran maíz, habas, arvejas, zapallo, alcayotas, choclos, papa, tomate, lechuga, cebolla, zanahoria y trigo, este último utilizado para la elaboración de harina y material para las techumbres. La finalidad de estos cultivos fue el consumo familiar y la diversificación alimentaria, pues en los poblados de Timar y Codpa se ha privilegiado el cultivo de frutales, y por tanto las hortalizas sembradas en Apanza permitían variar la dieta aprovechando además una nueva superficie de cultivo.

Al recorrer la quebrada actualmente es posible encontrar evidencia de las labores agrícolas con eras y chacras ${ }^{16}$ abandonadas (Figura $\mathrm{N}^{\circ} 2$ ) que ocupan una superficie aproximada de 35 ha. También existe evidencia de corrales donde se guardaban animales (mulas, caballos) utilizados para la carga de materiales que permitieron preparar los terrenos y también para la cosecha.

De acuerdo con los testimonios recogidos, el uso agrícola de los terrenos en Apanza se realizaba en los años que se esperaba fuese lluvioso, diagnóstico que realizaban los comuneros entendidos en la lectura de los señaleros ${ }^{17}$. Finalizado el tiempo de lluvias, aproximadamente en marzo,

\footnotetext{
En las comunidades andinas las chacras corresponden a áreas con fines productivos, culturales y simbólicos (Van Kessel y Condori 1992) donde además se habita.

17 Van Kessel y Salas, 2002
} 
los terrenos eran abandonados hasta una nueva temporada de avenida de agua, momento en que la recarga hídrica fuese suficiente y permitiera cultivar una vez más.

Figura $\mathrm{N}^{\circ} 2$

Eras en la Quebrada de Apanza ocupadas por agricultores de Timar (izquierda) y de Codpa (derecha)
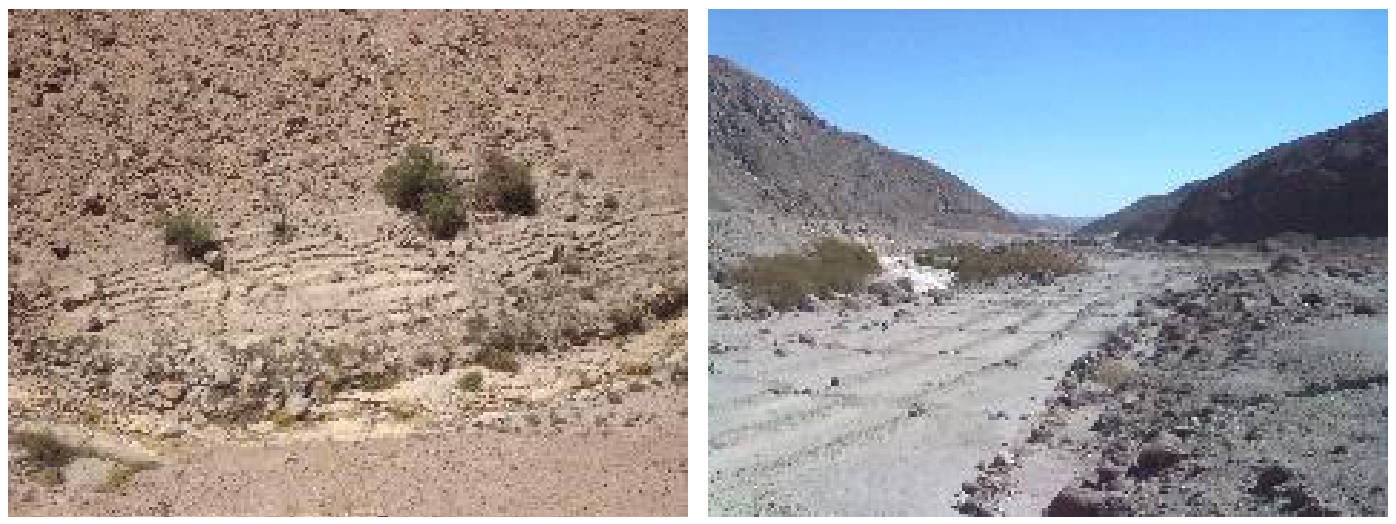

Fuente: Pereira, 2014.

Las personas entrevistadas mencionaron como principales causas del abandono de la práctica de los cultivos estacionales, la menor disponibilidad de agua y el desplazamiento de la población desde los poblados de origen hacia áreas urbanas, particularmente a la ciudad de Arica.

\section{Cultivos estacionales y manejo de crecidas en las cabeceras del valle de Azapa}

Los cultivos estacionales en la cabecera del valle de Azapa realizados por comuneros y comuneras de la quebrada de Livilcar, fue una práctica de la cual se tiene un amplio registro. Según investigaciones históricas (Durston \& Hidalgo, 2004) los comuneros de la quebrada de Livilcar fueron poseedores de tierras en el valle de Azapa y el valle de Lluta durante el periodo colonial. Estas tierras eran utilizadas como "islas" de cultivo, demostrando la existencia de una complementariedad entre distintos pisos ecológicos.

El desplazamiento desde los poblados de la quebrada de Livilcar hacia la cabecera del valle de Azapa para llevar a cabo los cultivos estacionales, se realizaba durante el periodo estival cuando bajaba el río San José. Según mencionan las personas entrevistadas que habitaban los poblados de Molino, Humagata y Ausipar; se acostumbraba a esperar la bajada del río San José con fogatas cercanas al lecho y al producirse los primeros "golpes de agua", el río era recibido con flores para que "el agua durara". Dependiendo de la cantidad y continuidad del flujo de agua del río se planificaban las áreas de cultivo y las cosechas, estas últimas estaban compuestas principalmente por zapallos, papas y otros tubérculos. La Figura $\mathrm{N}^{\circ} 3$ muestra vestigios de terrazas de cultivo y viviendas en Achuyo que fue afectado por la lloclla del año 1973, en la imagen se aprecia también el camino que era comúnmente utilizado antes de este evento y que fue remplazado por otro ubicado en la ladera sur de este sector de la quebrada. 
Figura $\mathrm{N}^{\circ} 3$

Terrazas de cultivo en Achuyo, Quebrada de Livilcar

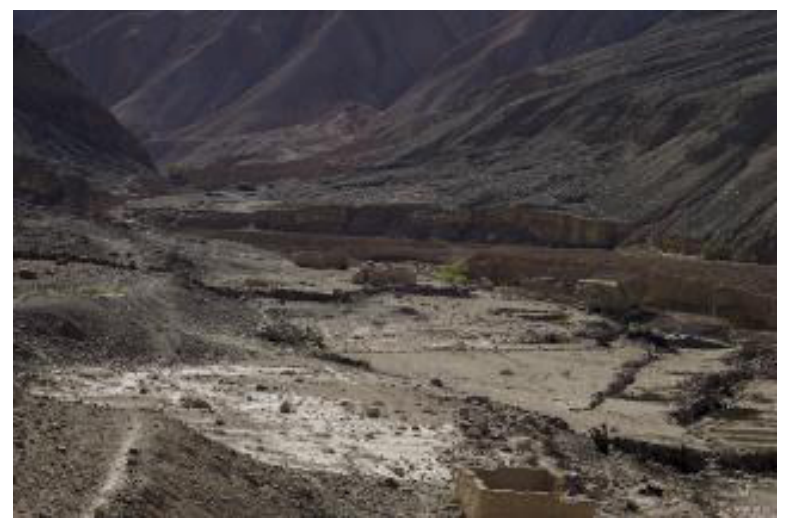

Fuente: Jofré, 2017.

El desplazamiento en el fondo de valle durante el periodo de avenidas y desencadenamiento de las Llocllas se veía fuertemente reducido, ya que el camino se inundaba haciendo imposible y peligroso su cruce a caballo o a pie. Para enfrentar estos eventos los pobladores de la quebrada utilizaron una extensa red de caminos alternativos situados en las laderas de los cerros, éstos permitieron unir distintos asentamientos cuando el camino del fondo de valle quedaba inhabilitado. Estos caminos conectaban además con otros pueblos cercanos y eran utilizados para bajar a los sectores de la cabecera de Azapa (Figura N4). A través de estos caminos, se movilizaban a caballo, burro, mula e incluso a pie, considerando que el recorrido por esta última alternativa podía demorar hasta dos días, lo cual demandaba organización para llevar alimento y agua suficiente, y también para calcular la llegada a los puntos de descanso.

\section{Figura $\mathrm{N}^{\circ} 4$}

Caminos alternativos. Molino a Patanjache (arriba) y tramo inicial de uno de estos caminos entre el pueblo de Livilcar y el Santuario de la Virgen de las Peñas (abajo)
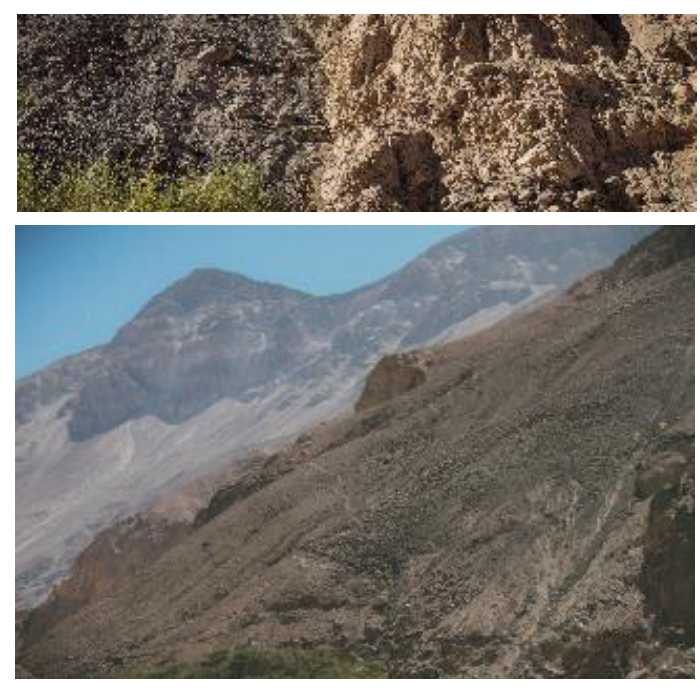

Fuente: Jofré, 2017. 
Las estrategias de aprovechamiento del agua para los cultivos estacionales, implicaba además el conocimiento de técnicas para mitigar la erosión de las terrazas provocada por la crecida del río San José, lo cual se hacía construyendo muros de contención entre las laderas y los terrenos de cultivos. En la Figura $\mathrm{N}^{\circ} 5$ (izquierda) es posible apreciar uno de estos muros que aún se mantiene en buen estado. También se utilizaron especies herbáceas como caña brava y árboles como tara y molle para arraigar los suelos durante las crecidas extremas del río ${ }^{18}$. Esta práctica se desarrolló a partir del conocimiento que tenía la comunidad sobre las raíces de estas especies que permitían "afirmar los suelos" ante la ocurrencia de fenómenos extremos de avenida.

\section{Figura $\mathrm{N}^{\circ} 5$}

Muro de defensa contra la erosión (izquierda) y desvío del río San José en Humagata (derecha)
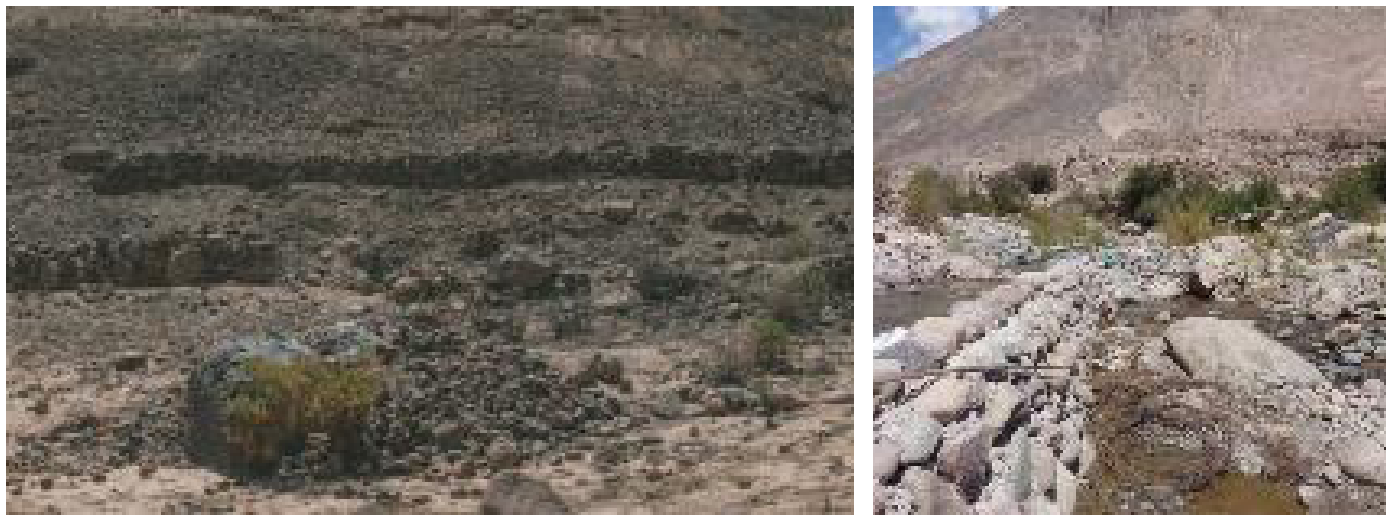

Fuente: Jofré, 2017.

Los cultivos estacionales se mantuvieron hasta el año 1962, año en que se canalizó el río Lauca, permitiendo el aumento del caudal del río San José y con ello los cultivos permanentes en todo el valle de Azapa.

\section{Escenarios climáticos pasados y esperados para el Norte Grande de Chile}

El sistema hídrico del Norte Grande recibe su mayor aporte de agua durante los meses de diciembre a marzo, periodo en que se producen precipitaciones de carácter convectivo en el altiplano, en tanto que la variabilidad micro-climática característica de la región andina se manifiesta en eventos hidrometeorológicos extremos que ocurren con cierta periodicidad tales como heladas, sequías, lluvias intensas e inundaciones, en periodos de larga duración, donde las precipitaciones estivales marcan la estacionalidad e irregularidad con que se alimentan las cuencas hidrográficas de las yungas secas.

A fines del año 1972 algunos pobladores de la quebrada de Livilcar se vieron afectados por una crecida extrema del río San José. Los llamados "damnificados de Livilcar" tuvieron que sustituir las tierras perdidas a causa de la crecida por tierras ubicadas en la cabecera del valle de Azapa (Platt, 1975) 
El Cuadro $N^{\circ} 1$ presenta los resultados de la aproximación a las características climáticas que a nivel regional estimularon el despliegue de prácticas y estrategias adaptativas a la variabilidad del clima en las yungas secas nortinas. Como el periodo de tiempo transita entre el siglo XVII y el XXI, asumimos que también permite un acercamiento a las actuales condiciones, es decir, al periodo de tiempo donde se produjo el desuso de dichas prácticas.

En la revisión de fuentes se hallaron mencionados distintos eventos desde el año 1693 al 2010, quedando reflejada la estacionalidad del régimen pluviométrico y la variabilidad climática del Norte Grande chileno, dada la recurrencia de sucesos extremos como aluviones o avenidas y sequías, concentrados preferentemente y al igual que hoy, entre los meses del verano austral. También es posible apreciar una alternancia de periodos secos y húmedos que se explican por la recurrencia de fenómenos El Niño y La Niña, los cuales asocian en esta zona, periodos de sequía y mayores precipitaciones en el altiplano, respectivamente.

Los eventos hallados en las fuentes han tenido distintos impactos sobre la población, infraestructura vial y viviendas de áreas urbanas y rurales debido al desencadenamiento de aluviones. De acuerdo con el registro grandes crecidas han afectado poblados, obligando incluso a su abandono temporal o permanente ${ }^{19}$, en tanto que las sequías han provocado daños en los cultivos, incitando incluso el desplazamiento de comunidade ${ }^{20}$ especialmente en la región de Tarapacá.

En la actualidad, las constantes crecidas del río San José en la región de Arica y Parinacota ${ }^{21}$ como consecuencia de las lluvias estivales en la franja andina, y que impactan directamente en las yungas secas, quebradas y valles de pisos ecológicos de menor altitud; constituyen eventos climáticos significativos de connotación negativa y catastrófica para la agricultura, población urbana localizada en el área de influencia de la desembocadura del río e infraestructura vial, paradójico si pensamos que en el pasado el excedente hídrico era esperado, beneficioso y manejado ya que ampliaba el acceso a recursos agrícolas.

\footnotetext{
A modo de ejemplo es posible mencionar el pueblo de Ticnamar en la precordillera de Arica, que tras una serie de inundaciones que arrasaron con la infraestructura y cultivos, se relocalizó en el año 1959. Más recientemente, en el año 2012, fenómenos aluvionales afectaron pueblos en la región de Tarapacá, con casos registrados en Camiña (Meza et al., 2014) y Laonzana (González, 2012).

20 Grebe, 1986, 1997-1998.

${ }^{21}$ Las que pueden ser de mayor o menor magnitud, estas últimas intercaladas por 4 a 5 años aproximadamente (MOP, 2010).
} 
Cuadro $\mathrm{N}^{\circ} 1$

Antecedentes documentales etnográficos de eventos climáticos en el Norte Grande de Chile

\begin{tabular}{|c|c|c|c|c|c|c|c|}
\hline Año & Evento climático & Lugar & Fuente & Año & Evento climático & Lugar & Fuente \\
\hline 1693 & $\begin{array}{l}\text { Seca de agua en } \\
\text { manantiales }\end{array}$ & Valle de Azapa & Keller, 1946: 49 & $\begin{array}{l}1970- \\
1972\end{array}$ & $\begin{array}{l}\text { Precipitaciones } \\
\text { muy escasas }\end{array}$ & Socoroma & $\begin{array}{l}\text { Choque y Pizarro, } \\
\text { 2013:67 }\end{array}$ \\
\hline 1695 & $\begin{array}{l}\text { Seca de agua en } \\
\text { manantiales }\end{array}$ & Valle de Azapa & Keller, 1946: 49 & 1973 & $\begin{array}{l}\text { Aluvión } \\
\text { catastrófico (enero) }\end{array}$ & Arica & Platt, 1975: 36 \\
\hline 1774 & $\begin{array}{l}\text { Seca de agua en } \\
\text { manantiales }\end{array}$ & Valle de Azapa & Keller, 1946: 49 & 1973 & 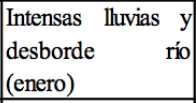 & $\begin{array}{l}\text { Precordillera de } \\
\text { Arica, río San José }\end{array}$ & $\begin{array}{l}\text { Urrutia y Lanza, } \\
\text { 1993: } 359\end{array}$ \\
\hline 1782 & Sequía & Valle de Azapa & Larraín, 1974: 141 & 1975 & \begin{tabular}{|lr} 
"invierno & \\
altiplánico" & $(22$ \\
enero), & lluvia \\
torrencial & \\
\end{tabular} & $\begin{array}{l}\text { Caseríos } \\
\text { Victoria y } \\
\text { (altiplano) }\end{array}$ & $\begin{array}{l}\text { Urrutia y Lanza, } \\
\text { 1993: } 363 \text { y } 364\end{array}$ \\
\hline 1819 & Fuerte avenida & Pampa Tamarugal & $\begin{array}{l}\text { Billinghurst, } 1886: \\
36\end{array}$ & 1975 & $\begin{array}{l}\text { Inundaciones } \\
\text { salitreras }\end{array}$ & $\begin{array}{l}\text { Salitreras de } \mathbf{M}^{\mathrm{a}} \\
\text { Elena, Coya Sur y } \\
\text { Pedro de Valdivia }\end{array}$ & $\begin{array}{l}\text { Urrutia y Lanza, } \\
1993: 363 \text { y } 364\end{array}$ \\
\hline 1823 & Fuerte avenida & Pampa Tamarugal & $\begin{array}{l}\text { Billinghurst, } \quad 1886: \\
36\end{array}$ & 1975 & Daños menores & $\begin{array}{ll}\text { Pozo } & \text { Almonte, } \\
\text { Mamiña, } & \text { Huara y } \\
\text { Camiña } & \\
\end{array}$ & $\begin{array}{l}\text { Urrutia y Lanza, } \\
1993: 363 \text { y } 364\end{array}$ \\
\hline 1852 & Avenida & Pampa Tamarugal & \begin{tabular}{|l|} 
Billinghurst, $1886:$ \\
36
\end{tabular} & 1975 & Ventarrón & Iquique & \begin{tabular}{|l|} 
Urrutia y Lanza, \\
$1993: 363$ y 364
\end{tabular} \\
\hline 1859 & Avenida & Pampa Tamarugal & \begin{tabular}{|l|} 
Billinghurst, $1886:$ \\
36
\end{tabular} & 1976 & $\begin{array}{|ll|}\begin{array}{l}\text { Fuertes } \\
\text { (enero) }\end{array} & \\
\end{array}$ & $\begin{array}{l}\text { Entre Arica y La } \\
\text { Serena }\end{array}$ & \begin{tabular}{|ll} 
Urrutia y & Lanza, \\
$1993: 365$ & \\
\end{tabular} \\
\hline 1868 & Avenida & Pampa Tamarugal & \begin{tabular}{|l|} 
Billinghurst, 1886: \\
36
\end{tabular} & 1976 & Desbordes & río San José & $\begin{array}{|ll|}\text { Urrutia y } & \text { Lanza, } \\
\text { 1993:365 } & \\
\end{array}$ \\
\hline 1878 & Avenida & Pampa Tamarugal & \begin{tabular}{|l|} 
Billinghurst, $\quad 1886:$ \\
36
\end{tabular} & 1979 & Sequía & Precordillera & Grebe, 1986: 208 \\
\hline 1884 & 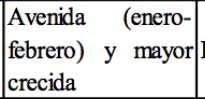 & Pampa Tamarugal & $\begin{array}{l}\text { Billinghurst, } \quad 1886: \\
36\end{array}$ & 1980 & No hubo lluvias & Socoroma & $\begin{array}{l}\text { Choque y Pizarro, } \\
\text { 2013: } 68\end{array}$ \\
\hline 1886 & Avenida & $\begin{array}{|ll|}\text { Quebrada } & \text { de } \\
\text { Tarapacá } & \\
\end{array}$ & $\begin{array}{l}\text { Riso Patrón, 1924: } \\
651\end{array}$ & 1987 & Temporal de lluvia & $\begin{array}{l}\text { Interior de Arica, } \\
\text { Parinacota }\end{array}$ & $\begin{array}{|ll|}\text { Urrutia y } & \text { Lanza, } \\
\text { 1993: } 383 & \\
\end{array}$ \\
\hline $\begin{array}{l}1904- \\
1911\end{array}$ & Prolongada sequía & Valle de Azapa & Keller, 1946: 138 & 1992 & $\begin{array}{|lr|}\text { Intensas } & \text { lluvias } \\
\text { (diciembre) } & y \\
\text { aumento caudal } & \text { y } \\
\end{array}$ & \begin{tabular}{|lr} 
Precordillera & de \\
Arica y río San \\
José
\end{tabular} & $\begin{array}{l}\text { Urrutia y Lanza, } \\
\text { 1993: } 399 \text { y } 400\end{array}$ \\
\hline 1906 & 3 días de lhuvia & Iquique & $\begin{array}{|ll|}\text { Urrutia y } & \text { Lanza, } \\
\text { 1993: } 157 & \\
\end{array}$ & 1992 & Frente mal tiempo & $\begin{array}{l}\text { Hasta Iquique y } \\
\text { Antofagasta }\end{array}$ & \begin{tabular}{|l|} 
Urrutia y Lanza, \\
1993: 399 y 400
\end{tabular} \\
\hline 1911 & $\begin{array}{l}\text { Copiosa lluvia (13 } \\
\text { enero) }\end{array}$ & $\begin{array}{|lll|}\begin{array}{l}\text { Lugares } \\
\text { pampa }\end{array} & \text { de la } \\
\end{array}$ & $\begin{array}{|ll|}\text { Urrutia y } & \text { Lanza, } \\
\text { 1993: } 174 & \\
\end{array}$ & 1992 & Lluvia intermitente & \begin{tabular}{|ll} 
Región de \\
Antofagasta
\end{tabular} & \begin{tabular}{|l|} 
Urrutia y Lanza, \\
1993: 399 y 400
\end{tabular} \\
\hline 1911 & \begin{tabular}{|l|} 
Inundaciones, \\
seguido de \\
tormenta de nieve \\
en la cordillera (15 \\
y 16 enero) \\
\end{tabular} & $\begin{array}{l}\text { Pozo Almonte, } \\
\text { Huara, Pisagua }\end{array}$ & $\begin{array}{l}\text { Urrutia y Lanza, } \\
\text { 1993: } 174\end{array}$ & 1992 & Tormenta eléctrica & $\begin{array}{l}\text { Visviri, Belén y } \\
\text { Tignamar }\end{array}$ & $\begin{array}{l}\text { Urrutia y Lanza, } \\
\text { 1993: } 399 \text { y } 400\end{array}$ \\
\hline 1944 & $\begin{array}{l}\text { Grandes avenidas y } \\
\text { cortes de camino } \\
\text { (verano) }\end{array}$ & $\begin{array}{l}\text { Quebradas de } \\
\text { Tarapacá y Aroma, } \\
\text { Huara y Quebrada } \\
\text { Seca }\end{array}$ & $\begin{array}{l}\text { Urrutia y Lanza, } \\
1993: 247 \text { y } 248\end{array}$ & 1992 & $\begin{array}{l}\text { Nevazón y bajas } \\
\text { temperaturas }\end{array}$ & $\begin{array}{l}\text { Chucuyo } \\
\text { Guallatire }\end{array}$ & $\begin{array}{l}\text { Urrutia y Lanza, } \\
\text { 1993: } 399 \text { y } 400\end{array}$ \\
\hline 1944 & $\begin{array}{l}\text { Aluvión ocasiona } \\
\text { daños (febrero) }\end{array}$ & Arica & $\begin{array}{l}\text { Urrutia y Lanza, } \\
\text { 1993: } 247 \text { y } 248\end{array}$ & 1992 & $\begin{array}{l}\text { Crecidas } \\
\text { inundaciones }\end{array}$ & $\begin{array}{l}\text { Estero Camiña, } \\
\text { Parca, Mamiña y } \\
\text { Cacaya }\end{array}$ & $\begin{array}{l}\text { Urrutia y Lanza, } \\
\text { 1993: } 399 \text { y } 400\end{array}$ \\
\hline $\begin{array}{l}1965- \\
1972\end{array}$ & Aguda sequía & $\begin{array}{l}\text { Precordillera } \\
\text { altiplano }\end{array}$ & $\begin{array}{l}\text { Quiroz et al., } \\
\text { 2015: } 160\end{array}$ & $\begin{array}{l}2003- \\
2010\end{array}$ & Sequía & $\begin{array}{l}\text { Socoroma, Belén y } \\
\text { comunidades de la } \\
\text { región }\end{array}$ & $\begin{array}{l}\text { Choque y Pizarro, } \\
\text { 2013: } 69\end{array}$ \\
\hline 1967 & 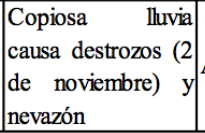 & Arica y Codpa & $\begin{array}{l}\text { Urrutia y Lanza, } \\
\text { 1993: } 333\end{array}$ & & & & \\
\hline
\end{tabular}


El Cuadro $\mathrm{N}^{\circ} 2$ presenta un resumen con los resultados de diversos estudios sobre las tendencias y proyecciones de las condiciones atmosféricas para el Norte Grande y el Altiplano de Chile.

La aproximación realizada transita entre inicios de la década de 1930 hasta el año 2013, destacando a largo plazo la ocurrencia de periodos secos y el descenso de las precipitaciones. Asimismo, los estudios muestran un aumento en la temperatura, lo que se relaciona con una menor disponibilidad hídrica para la agricultura en valles costeros y precordillera, y también para la ganadería altiplánica dado el aumento de la evaporación.

\section{Cuadro $\mathrm{N}^{\circ} 2$}

Tendencias y proyecciones climáticas para el altiplano y Norte Grande de Chile

\begin{tabular}{|c|c|c|c|}
\hline Periodo & Evento climático & Lugar & Fuente \\
\hline \begin{tabular}{|l|} 
Inicio década \\
1930, mediados \\
1940, mediados \\
$1975,1987-1992$ \\
\end{tabular} & Periodos anormalmente secos & $\begin{array}{l}\text { Altiplano } \\
\text { sudamericano }\end{array}$ & $\begin{array}{l}\text { Aceituno y Mon- } \\
\text { tecinos, } 1992\end{array}$ \\
\hline $1932-2000$ & $\begin{array}{l}\text { Declinación paulatina de precipita- } \\
\text { ciones a una tasa de } 0,83 \mathrm{~mm} \text { por } \\
\text { año }\end{array}$ & $\begin{array}{l}\text { Altiplano regiones de } \\
\text { Arica y Parinacota, y } \\
\text { Tarapacá }\end{array}$ & Gaete, 2005 \\
\hline 1979-2005 & $\begin{array}{l}\text { Aumento de temperatura significati- } \\
\text { vo (casi }+0,25^{\circ} \mathrm{C} \text { por década) }\end{array}$ & Sector cordillerano & Garreaud, 2011 \\
\hline $1984-2010$ & $\begin{array}{l}\text { Secuencias alternadas de años llu- } \\
\text { viosos y secos en todo (hasta } 5 \text { años } \\
\text { consecutivos de sequía meteoroló- } \\
\text { gica, y tres años seguidos de lluvia). }\end{array}$ & $\begin{array}{l}\text { Altiplano regiones de } \\
\text { Arica y Parinacota, y } \\
\text { Tarapacá }\end{array}$ & $\begin{array}{l}\text { Sarricolea y Ro- } \\
\text { mero, } 2015\end{array}$ \\
\hline 1966-2015 & Aumento temperaturas mínimas & Norte Grande & $\begin{array}{l}\text { Meseguer et al., } \\
2016\end{array}$ \\
\hline \multirow[t]{2}{*}{$1972-2013$} & Descenso precipitación & $\begin{array}{l}\text { Altiplano Norte } \\
\text { Grande }\end{array}$ & \multirow[t]{2}{*}{$\begin{array}{l}\text { Meseguer et al. } \\
2017\end{array}$} \\
\hline & Aumento precipitación & $\begin{array}{l}\text { Precordillera } \\
\text { de Tarapacá y } \\
\text { Antofagasta }\end{array}$ & \\
\hline
\end{tabular}

Fuente: Elaboración propia

Respecto de la temperatura para las próximas décadas, las estimaciones proyectan su aumento en la sección altiplánica del norte de Chile (Fuenzalida et al., 1989; CONAMA, 1999, 2006, 2008; IPCC, 2013; Ministerio de Medio Ambiente, 2017) y se señala que desde el año 1972 al 2013 ha ocurrido una significativa reducción de la precipitación anual en el Altiplano, esperándose que en las próximas décadas las lluvias se concentren en pocos días a fines del verano, que aumente la duración de los años secos y que se acentúen las variaciones topoclimáticas, lo que implica que lugares localizados en una misma latitud, pero con diferentes alturas o exposiciones, pueden incrementar o reducir sus precipitaciones (Meseguer et al., 2017).

Los periodos anormalmente secos y de declinación paulatina de las precipitaciones (década de 1930 hasta el año 2000, aproximadamente); coinciden con los años en que las personas situa- 
ron el inicio de los cultivos de temporada en Apanza (década de 1940), lo que de alguna forma valida el hecho de que el traslado de la población a las áreas urbanas, influyó más que el clima en el abandono de las prácticas adaptativas analizadas, pues la recurrencia de periodos de mayor y menor disponibilidad hídrica es constante, y continúa siendo una característica del clima de la región tal como en el pasado.

Asimismo, pese a las distintas magnitudes con que se puedan presentar periodos anormalmente secos, se puede apreciar cómo estos han permitido (y se podría decir que permitirían), el desarrollo de cultivos de temporada gracias al manejo del agua, pues esta práctica se originó por la lectura de la estacionalidad climática y aridez propia del área que las albergó, representando un proceso de ajuste efectivo al clima por parte de las comunidades. No obstante, al encontrarse en desuso y no ser replicadas por las generaciones depositarias de este conocimiento vernáculo, dado que en la actualidad es escasa la experiencia en el territorio que las estimuló, se pone en riesgo la capacidad adaptativa futura de las comunidades y de la población en general, por desconocimiento de estrategias que les permitan enfrentar la variabilidad del clima.

\section{Dinámica demográfica del área de estudio}

El desplazamiento de la población hacia centros urbanos ya sea de forma permanente o intermitente, fue mencionado por las personas entrevistadas como una importante causa que explicaría el abandono de los cultivos estacionales y las técnicas para el manejo de crecidas.

En efecto, desde la anexión de la actual región de Arica y Parinacota a los límites político-administrativos de Chile a fines del siglo XIX ${ }^{22}$, el Estado buscó legitimarse mediante dispositivos de control territoria ${ }^{23}$, siendo algunos de los hitos más emblemáticos la instauración en el año 1958 de un organismo político-administrativo con espíritu regionalista conocido como Junta de Adelanto de Arica (JAA) y la aplicación de políticas de excepción económica, lo que permitió dotar de mayores recursos a la región fortaleciendo la inversión en el puerto de Arica; especialmente en el sector de infraestructura, transformando a la ciudad en un foco de atracción laboral para la población rural. La ampliación de la ley de enseñanza básica obligatoria entre 1964-1970 también fue un importante factor de desplazamiento de población hacia la ciudad (Grebe, 1997).

La Figura $\mathrm{N}^{\circ} 6$ muestra cómo en los poblados de Codpa, Timar y Livilcar, la población ha disminuido notablemente si se compara el número de habitantes que había en el siglo XVIII con los de la actualidad, asimismo es posible observar que la dinámica demográfica presentó su mayor descenso entre los años cincuenta y noventa, periodo en que las comunidades andinas se involucran con mayor fuerza en las actividades de auge económico de los centros urbanos.

La concentración de actividades productivas y servicios en zonas urbanas y costeras, impactó directamente en la progresiva desruralización, descampesinización de la organización económica y translocalización de los patrones de relaciones sociales de las comunidades rurales

Pertenecía a Perú y luego de la guerra del Pacífico (1879-1883) se incorpora a Chile.

23 Proceso de chilenización (Ruz et al., 2015). 
(Gundermann, 2001; Carrasco \& González, 2014); dinámica que ha puesto en riesgo la capacidad adaptativa de las comunidades, debido a la conexión esporádica que actualmente existe con los territorios que estimularon estrategias particulares y comunitarias de manejo de los recursos, lo que se traduce en el olvido y pérdida de saberes locales de prácticas que demostraron ser exitosas en el pasado.

Aun cuando en Codpa el número de habitantes ha aumentado de acuerdo con el censo del año 2017, la población ya no recurre a nuevos espacios para ampliar su acceso a recursos agrícolas.

Figura $\mathrm{N}^{\circ} 6$

Dinámica de la población de Codpa, Timar y Quebrada de Livilcar

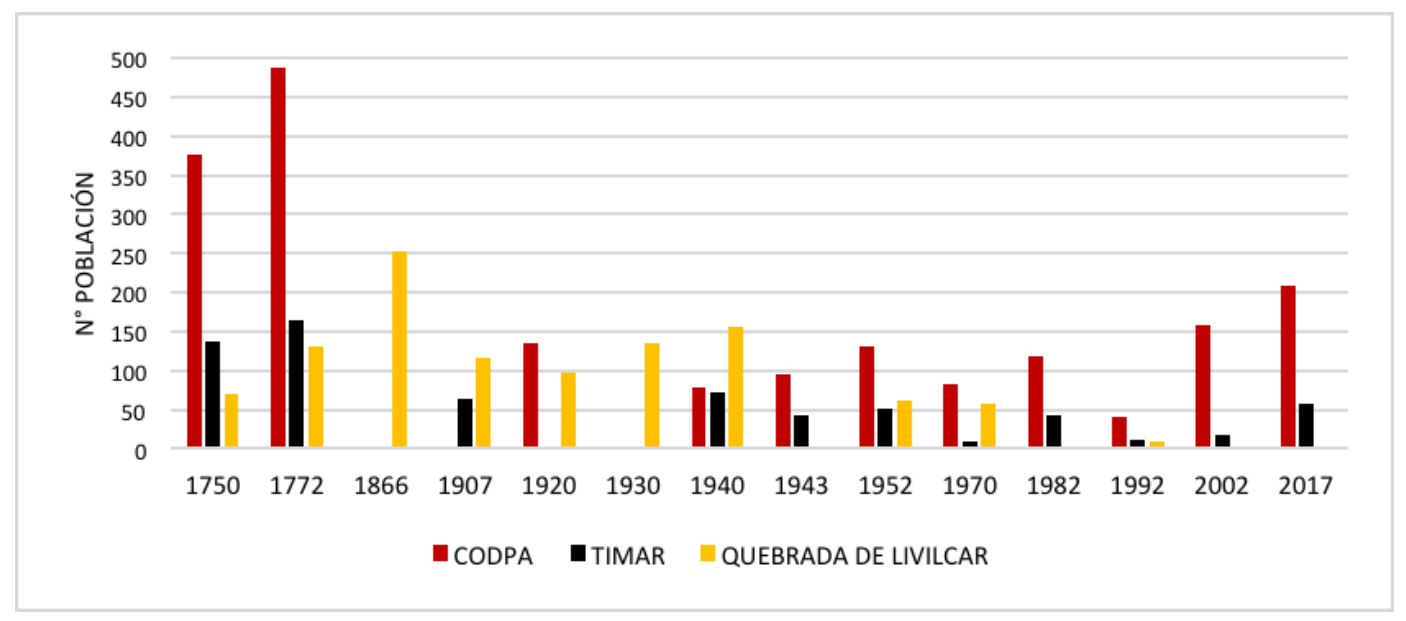

Fuente: Elaboración propia a partir de Keller, 1946; Servicio Nacional de Estadística y Censos, 1952; Hidalgo et al., 2004; Ruz et al., 2015; Instituto Nacional de Estadísticas, 2017.

\section{Conclusiones}

Los cultivos estacionales y el control de las crecidas de cursos superficiales e intermitentes de agua que practicaban las comunidades de Livilcar, Timar y Codpa; constituyen un ajuste a la mayor o menor disponibilidad del recurso hídrico concatenada a la alternancia de años secos y húmedos. Así como en el pasado, los antecedentes indican que las características climáticas del Norte Grande de Chile continuarán presentando ocurrencia de periodos secos y húmedos, en tanto que las proyecciones advierten sobre fenómenos de descenso de las precipitaciones, aumento de la temperatura, aumento de la evaporación y menor disponibilidad hídrica; escenario en el que cobra relevancia la capacidad que tendrán las comunidades para adaptarse a estas condiciones en un futuro no muy lejano.

En relación con la capacidad de respuesta de las comunidades, es imperativo comprender que esta se halla impregnada de memoria, y que los aprendizajes pasados pueden ser ajustados hoy para proyectarlos en función de los escenarios venideros. También lo es a la hora de tomar decisiones y planificar el uso de los territorios, pues en esta dirección, las estrategias de desarrollo y 
decisiones en la región de Arica y Parinacota, han tendido a fomentar brechas socio-espaciales, demográficas, económicas y culturales entre el desarrollo urbano y rural, igualando crecimiento económico con desarrollo social.

Dada esta lógica, en el Norte de Chile las obras de canalización de ríos se presentaron como un sistema de gestión racional del agua en un contexto de escasa disponibilidad hídrica; sin embargo, proyectos como el canal Lauca, han favorecido a grandes empresarios agrícolas en desmedro de los pequeños campesinos. El aumento de la producción sumado a la sobreexplotación del suelo en el valle de Azapa ha generado el desecamiento de bofedales en el Altiplano, cuyo resorte es la reterritorialización de comunidades aymaras en espacios urbanos al verse despojadas de sus medios de vida en la montaña.

Por otro lado, y como un síntoma más de las contradicciones de la racionalidad económica imperante, se aprecia que el excedente hídrico en el pasado era beneficioso y esperado; pues permitía ampliar los recursos agrícolas gracias al efectivo manejo y canalización del agua, esto a través de sistemas hídricos desarrollados, en el área de estudio, por las comunidades vinculadas a las quebradas de Apanza y Livilcar. En la actualidad la ocurrencia de avenidas de agua se relaciona con aluviones, desbordes de ríos e inundaciones; fenómenos percibidos como eventos perjudiciales, desastrosos y de connotación negativa para las comunidades.

La paradoja se impone cuando se aprecia cómo estas comunidades fueron capaces de beneficiarse de una situación aparentemente desventajosa mediante formas de mitigación basadas en el conocimiento del espacio geográfico, este último estimuló el manejo racional de los recursos disponibles en función de ciclos naturales, autogestión y organización comunitaria, diversificación espacio-temporal en la producción, búsqueda de caminos alternativos y generación de nuevos recursos.

En este sentido, el auge de la urbanización como mecanismo para crear el espacio de la modernidad, apartó la vida cotidiana de aquellos territorios que estimularon respuestas y estrategias adaptativas, limitando con ello las posibilidades de comprender y leer la naturaleza, lo que dificulta a su vez, la reproducción de conocimientos y prácticas tradicionales de manejo de recursos territoriales alternativos que demostraron ser efectivos en el pasado y que terminaron perdiendo su significado práctico.

En consecuencia, cuando la escasa experiencia en y con los territorios originarios convierte en riesgo de desastre la oportunidad de ajuste real o proyectado frente a la variabilidad del clima, lo que en definitiva está en riesgo es la capacidad adaptativa de las comunidades, ya que la experiencia urbana se inclina hacia un pensamiento unidimensional y materialista, donde se invalidan conocimientos que poseen valor más allá de la rentabilidad económica, periferizando el espacio rural y principalmente la montaña, espacios que se pretenden integrar, pero bajo lógicas mercantiles globales.

Será prioritario entonces avanzar hacia una adaptación basada en el conocimiento de las comunidades, pues el conjunto de saberes mediados por la experiencia de los sujetos en el territorio resultan ser estratégicos en esta materia, ya que como señala Pelling (2011), la adaptación al cambio climático se inicia con una comprensión de las estructuras existentes que permita consi- 
derar las experiencias previas, estas contribuirán a analizar críticamente las estructuras sociales para partir de lo ya existente, evitando aumentar la vulnerabilidad de las comunidades, lo cual es importante considerar a la hora de, por ejemplo, construir nuevos embalses, formular planes de adaptación al cambio climático o de repoblamiento del altiplano ariqueño.

\section{Referencias bibliográficas}

ACEITUNO, P. \& MONTECINOS, A. Precipitación en el Altiplano Sudamericano: variabilidad interanual e intraestacional y mecanismos asociados. Actas del I Congreso Iberoamericano de Meteorología-España, 1992, p. 330-336.

ACEITUNO, P. Elementos del clima en el Altiplano Sudamericano. Revista Geofísica, 1996, № 44, p. 37-55.

ADGER, N. Social and ecological resilience: are they related?. Progress in Human Geography, 2000, Vol. 24, N³, p. 347-364. doi: https://doi.org/10.1191/030913200701540465

BARRIENDOS, M. El clima histórico de Catalunya (siglos XIV-XIX). Fuentes, métodos y primeros resultados. Revista de Geografía, 1996-1997, №30-31, p. 69-96.

BARRIENDOS, M. \& MARTíN VIDE, J. Secular Climatic Oscillations as Indicated by Catastrophic Floods in the Spanish Mediterranean Coastal Area (14th-19th Centuries). Climatic Change, 1998, $N^{\circ} 38$, p. 473-491. doi: https://doi.org/10.1023/A:1005343828552

BERTONIO, L. Transcripción del Vocabulario de la Lengua Aymara 1612. La Paz-Bolivia: Radio San Gabriel, Republicado por Instituto de Lenguas y Literatura Andina-Amazónicas, 2011.

BILLINGHURST, G. Estudio sobre la geografía de Tarapacá (Páginas de un libro). Trabajo escrito para El Ateneo de lquique. Santiago de Chile: Imprenta de El Progreso, 1886.

CARRASCO, A. \& GONZÁLEZ, H. Movilidad poblacional y procesos de articulación rural- urbano entre los aymara del norte de Chile. Revista Si Somos Americanos, 2014, Vol. 14, № 2, p. 217-231.

COMISIÓN NACIONAL DEL MEDIO AMBIENTE [CONAMA]. Primera comunicación nacional bajo la Convención Marco de las Naciones Unidas sobre el cambio climático. Santiago de Chile: Ministerio de Medio Ambiente, 1999. Disponible en: http://www.compromisosclimaticos.cl/descargas/informes-de-monitoreo/1era-Comunicacion-Nacional-de-Chile-ante-la-Convencion-Marco-de-las-Naciones-Unidas-sobre-Cambio-Climatico_1999.pdf

COMISION NACIONAL DE MEDIO AMBIENTE [CONAMA]. Estudio de variabilidad climática en Chile para el siglo XXI (Informe final). Santiago de Chile: CONAMA, 2006.

COMISIÓN NACIONAL DEL MEDIO AMBIENTE [CONAMA]. Plan de Acción Nacional de Cambio Climático 2008 - 2012. Santiago de Chile: Ministerio de Medio Ambiente, 2008. Disponible en: http:// 
portal.mma.gob.cl/cambio-climatico/plan-de-accion-nacional-de-cambio-climatico-2008-2012pancc/

CHOQUE, C. \& PIZARRO, E. Identidades, continuidades y rupturas en el culto al agua y a los cerros en Socoroma, una comunidad andina de los Altos de Arica. Revista Estudios Atacameños, 2013, No45, p. 55-74. doi: http://dx.doi.org/10.4067/S0718-10432013000100005

DIRECCIÓN GENERAL DE AGUAS. Estimación de recargas en cuencas altiplánicas y precordilleranas de vertiente pacífica. Santiago de Chile: Ministerio de Obras Públicas, 2011.

DOLLFUS, O. El reto del espacio andino. Lima-Perú: Instituto de Estudios Peruanos, 1981

DURSTON, A. \& HIDALGO, J. La presencia andina en los valles de Arica, siglos XVI- XVIII: Casos de regeneración colonial de estructuras archipielágicas. En: HIDALGO, J. Historia Andina de Chile. Santiago de Chile: Editorial Universitaria, 2004, p. 472-479.

ERIKSEN, S. H.; NIGHTINGALE, A. J.; \& EAKIN, H. Reframing adaptation: The political nature of climate change adaptation. Global Environmental Change, 2015, №35, p. 523-533. doi: https://doi. org/10.1016/j.gloenvcha.2015.09.014

FUENZALIDA, H.; VILLAGRAN, C.; BERNAL, P.; FUENTES, E.; SANTIBAÑEZ, F.; PEÑA, H.; MONTECINO, V.; HAJEK, E.; \& RUTLLANT, J. Cambio climático global y eventuales efectos en Chile. Ambiente y Desarrollo, 1989, Vol. 2, p. 37-42.

GAETE, A. Análisis estadístico del comportamiento de las precipitaciones en el altiplano de Arica, provincia de Tarapacá (1932- 2000). Boletín de Geografía, 2005, № 22-23, p. 79-88.

GALLOPÍN, G. Linkages between vulnerability, resilience, and adaptive capacity. Global Environmental Change, 2006, No 16, p. 293-303. doi: https://doi.org/10.1016/j.gloenvcha.2006.02.004

GARCÍA, P. El estado chileno y la comunidad de Codpa. La constitución de la chilenidad durante las primeras décadas del siglo XX. Documentos y memoria. Tesis para optar al grado de Licenciado en Antropología. Valdivia: Universidad Austral de Chile, Facultad de filosofía y humanidades, 2008. $88 \mathrm{pp}$.

GARREAUD, R. Cambio Climático: Bases Físicas e Impactos en Chile. Revista Tierra Adentro - INIA, 2011, No. 93, p. 1-14.

GARREAUD, R.; VUILLE, M.; \& CLEMENT, A. The climate of the Altiplano: observed current conditions and mechanisms of past changes. Palaeogeography, Palaeoclimatology, Palaeoecology, 2003, Vol. 194, p. 5-22. doi: https://doi.org/10.1016/S0031-0182(03)00269-4

GONZÁLEZ, H. Timar, diagnóstico socio-económico acerca de la utilización de dos espacios económicos: el campo y la ciudad. Arica-Chile: Taller de Estudios Aymaras. Serie de documentos de trabajo, 1990. 
GONZÁLEZ, H., GUNDERMANN, H. \& HIDALGO, J. Comunidad indígena y construcción histórica del espacio entre los aymara del Norte de Chile. Revista Chungara, 2014, Vol. 46, N² 2, p. 113-164. doi: http://dx.doi.org/10.4067/S0717-73562014000200005

GONZÁLEZ, M. Los fenómenos aluvionales en el norte de Chile: el caso del poblado de Laonzana, Quebrada de Tarapacá. Memoria para optar al Título de Geógrafo. Arica: Universidad de Tarapacá, Facultad de Educación y Humanidades, 2012. 129 pp.

GUBER, R. La etnografía. Método, campo y reflexividad. Buenos Aires; Siglo XXI Editores, 2012.

GUNDERMANN, H. Comunidad, sociedad andina y procesos socio-históricos en el norte de Chile. Tesis de Doctorado en Ciencias Sociales con Especialidad en Sociología. Colegio de México, 2001. $490 \mathrm{pp}$.

GUTIÉRREZ, M. Geomorfología y cambio climático en zonas áridas. Academia de Ciencias Exactas, Físicas, Químicas y Naturales de Zaragoza. Zaragoza: Sociedad Cooperativa de Artes Gráficas, 1998.

GREBE, M. Migración, identidad y cultura: puntos de vista del actor. Revista Chungara, 1986, №1617, p. 205-223.

GREBE, M. Procesos migratorios, Identidad étnica y estrategias adaptativas en las culturas indígenas de Chile: Una perspectiva preliminar. Revista Chungara, 1997-1998, №14, p. 55-68. doi: 10.5354/0719-1472.2011.17502

GRUPO INTERGUBERNAMENTAL DE EXPERTOS SOBRE CAMBIO CLIMÁTICO [IPCC]. Cambio climático 2013: Bases físicas. Resumen para responsables de políticas. Ginebra: Contribución del Grupo de trabajo I al Quinto Informe de Evaluación del Grupo Intergubernamental de Expertos sobre el Cambio Climático, 2013. Disponible en: https://www.ipcc.ch/pdf/assessment-report/ar5/wg1/ WG1AR5_SPM_brochure_es.pdf

HIDALGO, J.; CASTRO, N.; \& GONZALEZ, S. La revisita de Codpa (Altos de Arica) de 1772-73 efectuada por el corregidor Demetrio Egan. Revista Chungara, 2004, Vol. 36, No1, p. 103-204. doi: http://dx.doi.org/10.4067/S0717-73562004000100005

HOFSTEDE, R. Adaptación al cambio climático basada en los conocimientos tradicionales. En: Lara, R. y Vides-Almonacid, R. (Editores). Sabiduría y Adaptación. El Valor del Conocimiento Tradicional para la Adaptación al Cambio Climático en América del Sur. Quito-Ecuador: UICN, 2014, p. 59-79.

INSTITUTO NACIONAL DE ESTADísTICAS [en línea] [fecha de consulta 3 de julio de 2018]. Disponible en: https://www.censo2017.cl/

JOFRÉ, J. Saberes locales y desarrollo de estrategias de adaptación ante la variabilidad climática en la quebrada de Livilcar. Memoria para optar al título de geógrafo. Arica: Universidad de Tarapacá, Facultad de Educación y Humanidades, 2017. 
KELLER, C. El Departamento de Arica. Santiago de Chile: Ministerio de Economía y Comercio, 1946.

KLOHN, W. Hidrografía de las zonas desérticas de Chile. Santiago de Chile: Investigaciones de los recursos hidráulicos en el Norte Grande, Programa de las Naciones Unidas para el Desarrollo, 1972.

LARRAÍN, H. Análisis de las causas de despoblamiento entre las comunidades indígenas del Norte de Chile, con especial referencia a las hoyas hidrográficas de las Quebradas Aroma y Tarapacá. Revista de Geografía Norte Grande, 1974, № 2, p.125-154.

MARTÍN VIDE, J. \& BARRIENDOS, M. The use of rogation ceremony records in climatic reconstruction: a case study from Catalonia (Spain). Climatic Change, 1995, N³0, p. 201-221. doi: https:// doi.org/10.1007/BF01091842

MCDOWELL, J. \& HESS, J. Accessing adaptation: Multiple stressors on livelihoods in the Bolivian highlands under a changing climate. Global Environmental Change, 2011, Vol. 22, p. 342-352. doi: https://doi.org/10.1016/j.gloenvcha.2011.11.002

MESEGUER, O.; CORVACHO, O.; TAPIA, A.; LÓPEZ, J.; \& SARRICOLEA, P. Tendencias de la temperatura mensual y de los extremos diarios durante el periodo 1966-2015 en el Norte Grande chileno. En: $X$ Congreso de la Asociación Española de Climatología: 5 a 8 de octubre. Alicante, 2016, pp. 257-266.

MESEGUER, O.; CORVACHO, O.; TAPIA, A.; LÓPEZ, J.; \& SARRICOLEA, P. Análisis de las temperaturas medias y sus extremos a partir de diferentes índices durante el período 1966-2015 en el norte grande chileno. Revista Diálogo Andino, 2017, № 54, p. 31-40.

MEZA, M.; RODRÍGUEZ, A.; CORVACHO, O.; \& TAPIA, A. Análisis morfométrico de microcuencas afectadas por flujos de detritos bajo precipitación intensa en la quebrada de Camiña, Norte Grande de Chile. Revista Diálogo Andino, 2014, № 44, p. 15-24.

MINISTERIO DE OBRAS PUBLICAS [MOP]. Plan de acción estratégico para el desarrollo hídrico de la región de Arica y Parinacota (Documento propuesta borrador). Santiago de Chile: División de estudio y planificación, Dirección General de Aguas, 2010.

MINISTERIO DEL MEDIO AMBIENTE [MMA]. Plan de Acción Nacional de Cambio Climático 20172022. Santiago de Chile: MMA, 2017.

MUÑOZ, I.; CHACAMA, J.; \& ESPINOZA, G. El poblamiento prehispánico tardío en el Valle de Codpa: Una aproximación a la historia regional. Revista Chungara, 1987, № 19, p. 7-61.

MUÑOZ, I. \& CHACAMA, J. Áreas de actividad y arquitectura doméstica en el poblado de Pubrisa durante la influencia incaica. Revista Estudios Atacameños, 2007, №34, p. 97-112. doi: http://dx. doi.org/10.4067/S0718-10432007000200006.

MURRA, J. El "control vertical" de un máximo de pisos ecológicos en la economía de las sociedades andinas. En: MURRA, J. El mundo andino: población, medio ambiente y economía. Lima-Perú: 
Instituto de Estudios Peruanos. Pontificia Universidad Católica del Perú (Historia Andina 24), 2002, p. 85-125.

NELSON, D. Adaptation and resilience: responding to a changing climate. WIREs Climate Change, 2011, Vol. 2, p. 113-120. doi: https://doi.org/10.1002/wcc.91

NOBLET, M.; GUILLEMOT, J. \& CHOUINARD. O. Rôle de l'action collective et du capital social dans les processus d'adaptation au changement climatique en zone côtière - Comparaison de deux études de cas au Nouveau-Brunswick (Canada). Développement durable et territoires, 2016, Vol. 7, $N^{\circ} 2$, p. 1-19. doi: https://doi.org/10.4000/developpementdurable.11297

PELLING, M. Adaptation to climate change: From resilience to transformation. London: Routledge, 2011.

PEREIRA, K. Adaptación a la variabilidad climática. Caso de los cultivos estacionales en la quebrada de Apanza, cuenca de Codpa, región de Arica y Parinacota. Memoria para optar al título de Geógrafa. Arica: Universidad de Tarapacá, Facultad de Educación y Humanidades, Departamento de Ciencias Históricas y Geográficas. 2014. 74 pp.

PULGAR, J. Las ocho regiones naturales del Perú. Revista. Revista Terra Brasilis (Nova Série), 2014, No3, p. 1-20.

PLATT, T. Experiencia y experimentación: Los asentamientos andinos en las cabeceras del valle de Azapa. Revista Chungara, 1975, N 5, p. 33-60.

QUIROZ, D.; DÍAZ, A.; GALDAMES, L.; \& RUZ, R. Campesinos andinos y políticas agrarias durante la Junta de Adelanto de Arica (Azapa, Lluta y la Precordillera, 1959-1976). En: RUZ, R., GALDAMES, L. Y DÍAZ, A. (compiladores): Junta de Adelanto de Arica (1958-1976). Experiencia, documentos e historia regional. Arica-Chile: Universidad de Tarapacá, 2015, p. 105-127.

REYES, A. Estructura del paisaje cultural de la quebrada de Livilcar y sus prospecciones territoriales ante la construcción del embalse del río San José. Memoria para optar al título de Geógrafa. Arica: Universidad de Tarapacá, Facultad de Educación y Humanidades, Departamento de Ciencias Históricas y Geográficas. 2011. 116 pp.

RÍOS, W. \& PIZARRO, E. Cultivos prehispánicos: El caso de la coca en el extremo norte de Chile (S. XVI). Revista Diálogo Andino, 1988-1989, N 7-8, p. 82-99.

RISO, L. Diccionario Jeográfico de Chile. Santiago de Chile: Imprenta Universitaria, 1924.

ROMERO, H.; SMITH, P.; MENDONÇA, M.; \& MÉNDEZ, M. Macro y mesoclimas del altiplano andino y desierto de Atacama: desafíos y estrategias de adaptación social ante su variabilidad. Revista de Geografía Norte Grande, 2013, №55, p. 19-41. doi: http://dx.doi.org/10.4067/S071834022013000200003 
ROMERO, H.; ESPINOZA, G.; OPAZO, D.; \& SEPÚLVEDA, D. Topoclimatología cultural y cambios de clima en la zona andina del Norte de Chile. En: Sánchez, R., Arenas, F., Hidalgo, R. (Editores). Re-conociendo las Geografía de América Latina y El Caribe. Santiago de Chile: Ediciones de la Pontificia Universidad Católica de Chile, 2017, p. 93-131. Disponible en: https://www.uibk.ac.at/ geographie/personal/borsdorf/pdfs/libro-re-conociendo-1.pdf

RUTLLANT, J.; ACEITUNO, P.; \& MONTECINOS, A. Análisis comparativo de aspectos atmosféricos para los eventos El Niño/Oscilación del Sur de 1982-83, 1986-87 y 1991-92. Investigaciones Pesqueras, 1992, Vol. 37, p. 45-54.

RUZ, R.; DÍAZ, A.; \& GALDAMES, L. Gente de las Alturas Población Andina de la Precordillera y Altiplano de Arica. El Censo de 1866. Arica-Chile: Ediciones Universidad de Tarapacá, 2015. Disponible en: https://www.researchgate.net/publication/319987316_GENTE_DE_LAS_ALTURAS_POBLACION_ANDINA_DE_LA_PRECORDILLERA_Y_ALTIPLANO_DE_ARICA_EL_CENSO_DE_1866

SANTORO, C.; NÚÑEZ, L.; STANDEN, V.; GONZÁLEZ, H.; MARQUET, P.; \& TORRES, A. Proyectos de irrigación y la fertilización del desierto. Revista Estudios Atacameños, 1998, №16, p. 321-336.

SARRICOLEA, P. \& ROMERO, H. Variabilidad y cambios climáticos observados y esperados en el Altiplano del norte de Chile. Revista de Geografía Norte Grande, 2015, № 62, p. 169-183.

SERVICIO NACIONAL DE ESTADÍSTICA Y CENSOS. Censo de población y vivienda 1952. Disponible en: http://historico.ine.cl/canales/usuarios/cedoc_online/censos/pdf/censo_1952.pdf

TABERNA, F. y Comisión Organizadora del I Congreso del Hombre Andino [1973] "El rol de la sociedad andina y el tránsito al socialismo". En: Guerrero, B. (ed.) Homenaje a Freddy Taberna G. Escritos sobre la sociedad aymara del Norte Grande de Chile. Iquique-Chile: CREAR-El Jote Errante, 1996, p. 47-65.

TARQUE, H. Huellas de Livilcar. Arica-Chile: CONADI, 2016.

URRUTIA, R. \& LANZA, C. Catástrofes en chile 1541-1992. Santiago de Chile: Editorial La Noria, 1993.

URZÚA, L. Arica, puerta nueva: historia y folklore. Santiago de Chile: Andrés Bello, 1969.

VAN KESSEL, J. \& CONDORI, D. Criar la Vida. Trabajo y Tecnología en el Mundo Andino. Santiago de Chile: Vivarium, 1992.

VAN KESSEL, J. \& SALAS, P.E. Señas y Señaleros de la Santa Tierra. Agronomía Andina. Holanda: Departamento de Sociología Rural de la Universidad de Wageningen, Número 4 de la Serie: "Wageningen studies on heterogeinity and relocalization", 2002.

YÁÑEZ, N. \& Y. MOLINA. Las aguas indígenas en Chile. Santiago de Chile: Editorial LOM, 2011. 
